\title{
BMJ Open Association among work exposure, alcohol intake, smoking and Dupuytren's disease in a large cohort study (GAZEL)
}

\author{
Alexis Descatha, ${ }^{1,2,3}$ Matthieu Carton, ${ }^{1,2}$ Zakia Mediouni, ${ }^{1,2,3}$ Christian Dumontier, ${ }^{4}$ \\ Yves Roquelaure, ${ }^{5}$ Marcel Goldberg, ${ }^{1,2}$ Marie Zins, ${ }^{1,2}$ Annette Leclerc ${ }^{1,2}$
}

To cite: Descatha A, Carton M, Mediouni Z, et al. Association among work exposure, alcohol intake, smoking and Dupuytren's disease in a large cohort study (GAZEL). BMJ Open 2014:4:e004214.

doi:10.1136/bmjopen-2013004214

- Prepublication history for this paper is available online. To view these files please visit the journal online (http://dx.doi.org/10.1136/ bmjopen-2013-004214).

Received 10 0ctober 2013 Revised 9 December 2013 Accepted 20 December 2013

CrossMark

For numbered affiliations see end of article.

Correspondence to Professor Alexis Descatha; alexis.descatha@uvsq.fr

\section{ABSTRACT}

Objectives: In view of the debate of factors in Dupuytren's disease, we aimed to describe its relationship with certain occupational factors, alcohol intake and smoking.

Setting: The French GAZEL cohort (employees of Electricité de France and Gaz de France).

Participants: Participants of the cohort who answered a questionnaire in 2012, that is, 13587 participants ( $73.7 \%$ of the questionnaire sent). In 2007, self-assessed lifetime occupational biomechanical exposure was recorded (carrying loads, manipulating a vibrating tool and climbing stairs), as well as alcohol intake, smoking and diabetes mellitus. Analyses were performed on high alcohol intake, smoking and duration of relevant work exposure, stratified by gender.

Primary and secondary outcome measures:

From a specific question on Dupuytren's disease assessed in 2012, the outcome measures were selfreported Dupuytren's disease (yes/no) and disabling Dupuytren's disease (including surgery).

Results: A total of 10017 men and 3570 women, aged 64-73 years, were included; the mean age for men was 68 years and for women was 65 years. Among men, the following were significantly associated with Dupuytren's disease: age (OR 1.03 $(1.00 ; 1.06))$, diabetes (OR $1.31(1.07 ; 1.60))$, heavy drinking (OR $1.36(1.10 ; 1.69))$ and over 15 years of manipulating a vibrating tool at work (OR 1.52 (1.15; 2.02)); except for diabetes, the association with these factors was stronger for disabling Dupuytren's disease (or surgery), with OR 1.07 (1.03; 1.11), 1.71 (1.25; $2.33)$ and $1.98(1.34 ; 2.91)$, respectively, for age, heavy drinking and over 15 years of manipulating a vibrating tool at work. Among the 3570 women included, 160 reported Dupuytren's disease (4.5\%). The number of cases in the group of women was too low to reach conclusions, although the findings seemed similar for age, diabetes and vibration exposure.

Conclusions: In this large French cohort study, Dupuytren's disease in men was associated with high levels of alcohol consumption and exposure to handtransmitted vibration. It is likely that the same applied to women.

\section{Strengths and limitations of this study}

- Limitation: Self-reported diagnosis, and possible residual confounding (genetic factors mainly).

- Strength: The longitudinal design the relatively large size of the cohort.

- Strength: Analyses on women.

Dupuytren's disease is characterised by chronic contracture of the fourth and fifth fingers of the hand towards the palm, usually accompanied by thickening of the palmar skin. ${ }^{1}$ It has a clear genetic background. ${ }^{2-4}$

Since its description by Guillaume Dupuytren in 1831 following Henry Cline senior and Sir Astley Cooper, there has been controversy regarding biomechanical work exposure which might contribute to the development of this disorder. ${ }^{5}$ An exhaustive review and a meta-analysis were conducted to address this controversy, and was concluded that there is good evidence of an association between vibration exposure and Dupuytren's disease. ${ }^{6}{ }^{7}$ However, some authors still consider that occupational exposure, including vibration, is not a risk factor for Dupuytren's disease in manual workers. ${ }^{1} 8{ }^{8}$ These authors argued there are still conflicting results and that evidence is based only on two longitudinal studies. The role of alcohol consumption and smoking are also a matter of debate, ${ }^{9}{ }^{10}$ although one large longitudinal study found a clear relationship between such exposure and Dupuytren's disease. $^{11}$

We used data from a large cohort study to describe the prevalence of Dupuytren's disease, and to analyse its association with certain risk factors, including exposure to vibration, alcohol intake and smoking. 


\section{METHODS}

\section{Population}

The GAZEL cohort comprises employees of Electricité de France (EDF) and Gaz de France (GDF), the French national utility for energy production and distribution (GAZEL stands for GAZ and ELectricité). The company employs workers in various trades and of different socioeconomic status. At baseline in 1989, the cohort included 20625 volunteers, men aged $40-50$ years and women 35-50 years, and 18428 of them are still followed up. In January of each year since then, the participants have completed a general self-administered questionnaire about their lifestyle, health and occupational situation. $^{12}$

In the present study, we included only the participants who answered the 2012 GAZEL questionnaire (which included a question about Dupuytren's disease).

\section{Potential risk factors}

Information on gender and age (in 2012) was collected through the general questionnaire. Occupational risk factors were assessed in the 2007 questionnaire. Data on nine different types of biomechanical exposure were available, including the number of years of exposure during their working lives (carrying loads, bending trunk, drive a vehicle, kneeling, climbing stairs, climbing ladder, working with arm over the shoulder, carrying load on the shoulder and manipulating a vibrating tool). In this study of Dupuytren's disease, we analysed the potential role of manipulating a vibrating tool. As information about forceful activity was not available, carrying loads was considered to be a proxy for forceful work and was also taken into account. Climbing stairs, an irrelevant exposure for Dupuytren's disease, was also used as a 'control exposure' to check the lack of relationship. For these variables, three categories were considered for men based on duration of exposure: that is, never exposed, exposed but for less than 15 years and exposed for 15 years or more. In view of the number of exposed women in the cohort, the exposure for women was only considered as yes or no. In addition, at inception of the cohort in 1989, a 'yes or no' question about manipulating vibrating tools was also available, and computer work was used as control exposure.

Data for alcohol consumption were available for each year since 1992, and three categories were also considered on the basis of the distribution observed. Only heavy drinkers were taken into account based on the results of a previous study ${ }^{13}$ : less than 3 glasses a day of any alcohol, 3-4 glasses of wine or beer, 5 or more glasses of wine/beer or 3 glasses or more of spirits a day. If a participant had increased his alcohol consumption between 1992 and 2012, the highest category was taken into consideration. Data on smoking had been collected at inception in 1989 and grouped into three categories: non-smoker or former smoker, 1-20 cigarettes/cigars or pipes per day and over 20 cigarettes/cigars or pipes per day. As for alcohol consumption, the highest alcohol-intake category was taken into consideration if the participant had increased consumption during the study period.

Diabetes mellitus was self-reported every year from 1989.

\section{Outcomes}

In 2012, a specific question on Dupuytren's disease was asked: "(1) Have you ever had Dupuytren's disease (thickening of the palmar skin, nodes or contracture of the fourth finger of the hand)? (2) if yes, do you have any limitations because of it? (3) Have you had surgery for it?"

We considered two outcomes, that is, Dupuytren's disease (yes or no) based on the answer to the first question; and a three-category variable: no Dupuytren's disease (reference), Dupuytren's disease without surgery and without limitations and Dupuytren's disease with surgery or limitations.

\section{Analyses}

Univariate and multivariate analyses were stratified on gender for both outcomes. For the multinomial regression model, all the risk factors previously described were included, except 'control exposure' variables. Statistical Analysis Software was used for all statistical analyses (SAS, V.9.3, SAS Institute Inc, Cary, North California, USA). Associations were considered statistically significant if the $p$ value was less than 0.05 . OR and their $95 \%$ CI were computed.

\section{RESULTS}

The 13587 participants who answered the GAZEL questionnaire in 2012 constituted the sample (10 017 men and 3570 women). The participation rate was $73.7 \%$ (18 428 questionnaires sent in 2012). The participants were aged 59-73 years (mean age 68 years for men and 65 years for women).

Of the 10017 men included, 839 reported Dupuytren's disease $(8.4 \%)$, including 342 who reported surgery or limitations $(3.4 \%)$. Age, diabetes mellitus, heavy drinking and over 15 years of manipulating a vibrating tool at work were significantly associated with self-reported Dupuytren's disease, with a dose-effect relationship (table 1). Similar results were found when a yes/no question was used at the inception of the cohort in 1989. As expected, none of the 'control exposure' variables were associated with Dupuytren's disease. Reported durations of exposure to carrying loads and smoking habits were not found to be associated with Dupuytren's disease. The associations were stronger when considering disabling Dupuytren's disease (or surgery) than for Dupuytren's disease without reported surgery or disability (table 2). Figure 1 shows a clear dose effect in relation to duration of exposure, using a 5 -year step. 
Table 1 Univariate and multivariate analyses of Dupuytren's disease (yes vs no) and available factors assessed in the previous period in men

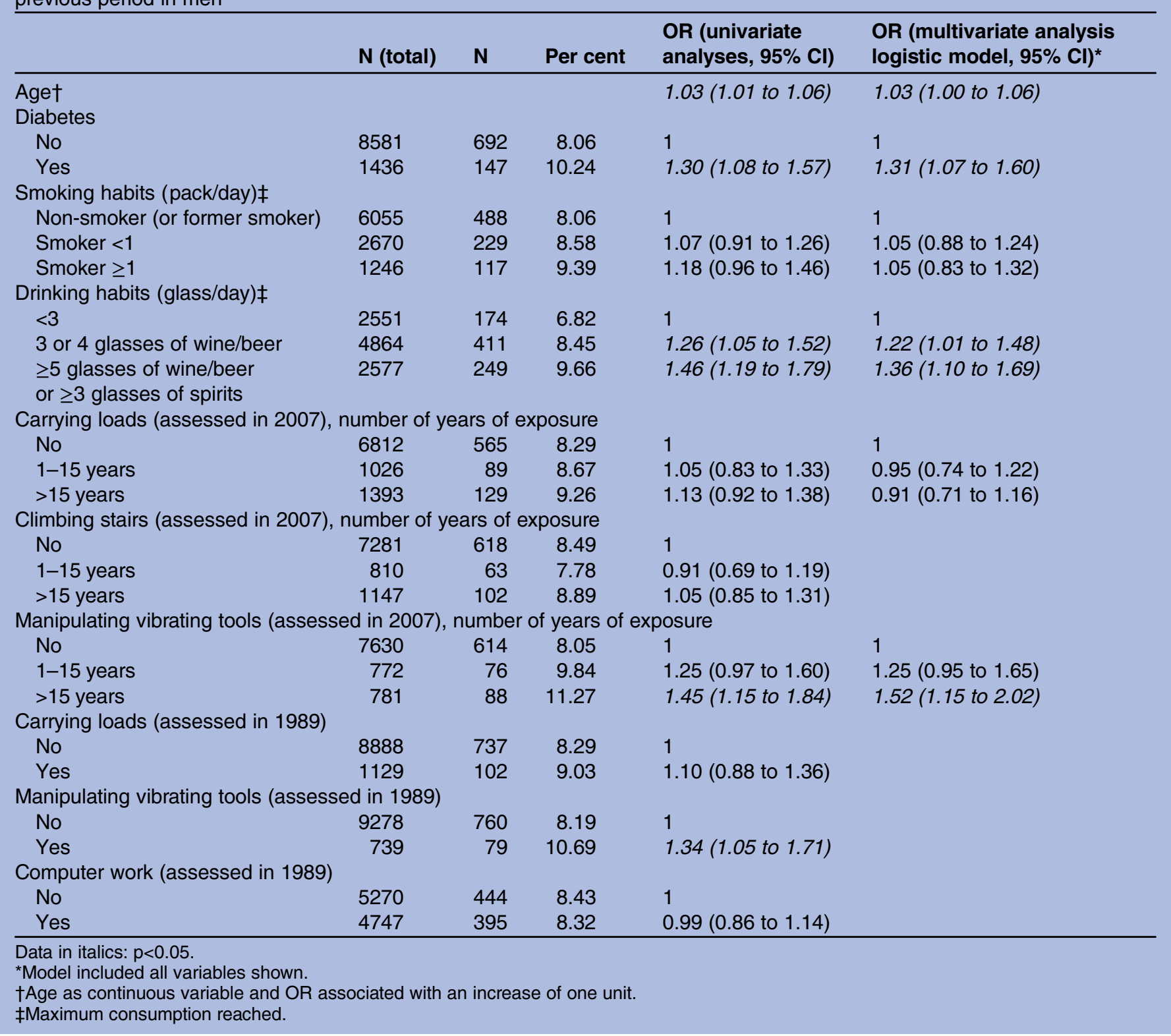

Of the 3570 women included, 160 reported Dupuytren's disease $(4.5 \%)$, including 78 who reported surgery or limitations $(2.2 \%)$. Associations were found to be weak, although age, diabetes and vibration exposure were still significant (tables 3 and 4); however, only a small number of women were heavy drinkers or occupationally exposed.

\section{DISCUSSION}

The study confirmed that Dupuytren's disease in men is associated with high levels of alcohol consumption and exposure to hand-transmitted vibration in this large French cohort study, after adjustment for age and diabetes, whereas smoking habits and other types of occupational exposure were not. This is one of the first studies to analyse risk factors among women, the number of exposed cases was too small to draw any conclusion, although associations appeared similar to those observed in men.

The study had some limitations. The major limitation came from the fact that the diagnosis was self-reported, without any confirmation by physical examination by a physician. In most cases, Dupuytren's disease is easily diagnosed, with no major differential diagnoses, although it might be a previous hand trauma, camptodactyly and tendovaginitis stenosans in a fixed flexion position, for example. In addition, we considered the fourth digit only. ${ }^{14}$ This lack of confirmation may have led to an underestimation of the prevalence of the disorder but it was probably limited, considering that the prevalence of this disorder in our study was comparable with that observed for the same age category in the general population. ${ }^{9}{ }^{15}$ A possible residual confounding effect should also be discussed: information regarding 
Table 2 Univariate and multivariate analyses of Dupuytren's disease (without limitations or surgery, with limitations or surgery, compared with reference class: no Dupuytren's disease) and available factors assessed in the previous period in men

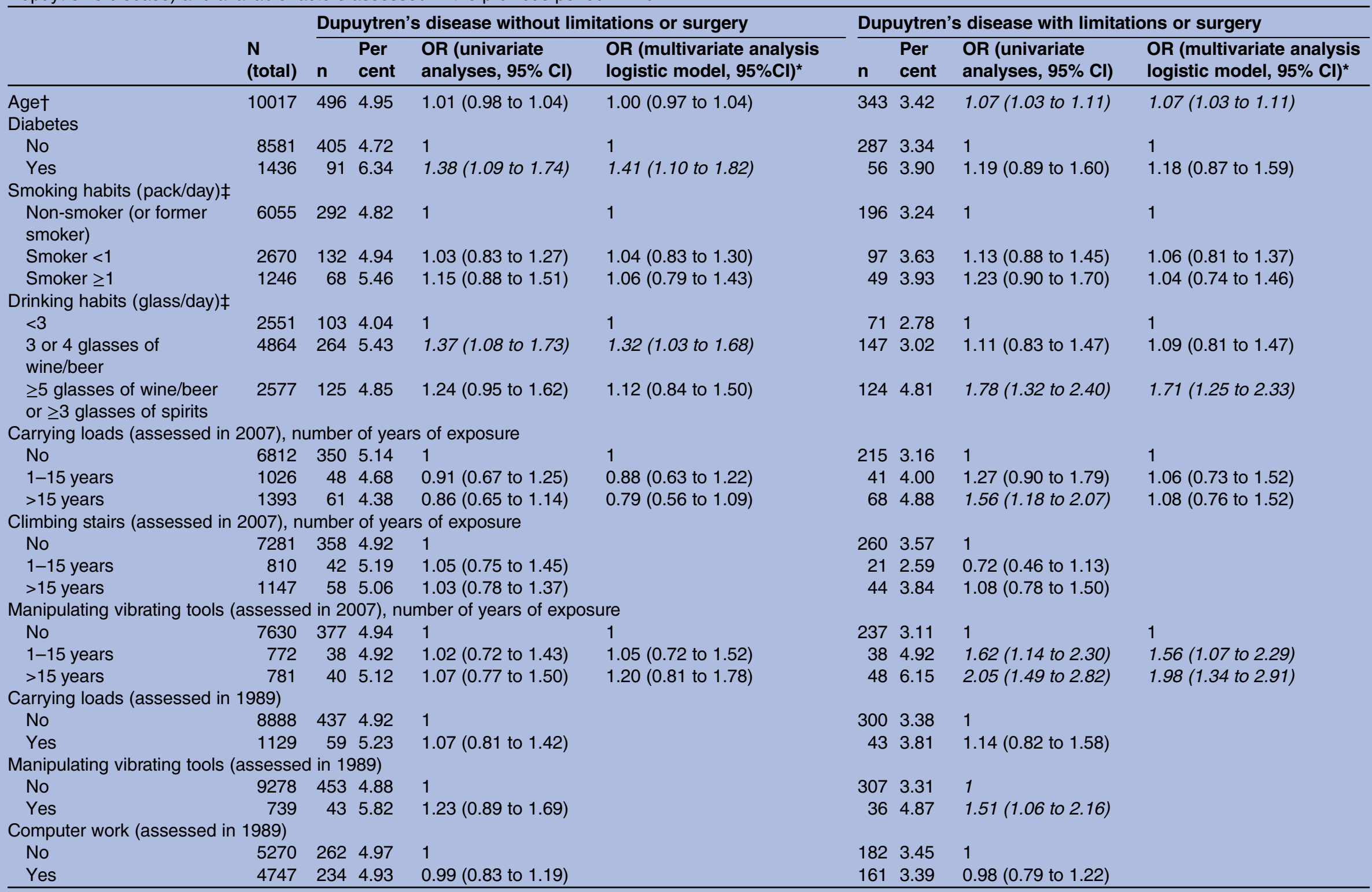

Data in italics: $p<0.05$.

*Model included all variables shown.

†Age as continuous variable and OR associated with an increase of one unit.

†Maximum consumption reached. 
Figure 1 Proportion of

Dupuytren's disease depending on duration of vibration exposure in the working life (5-year step).

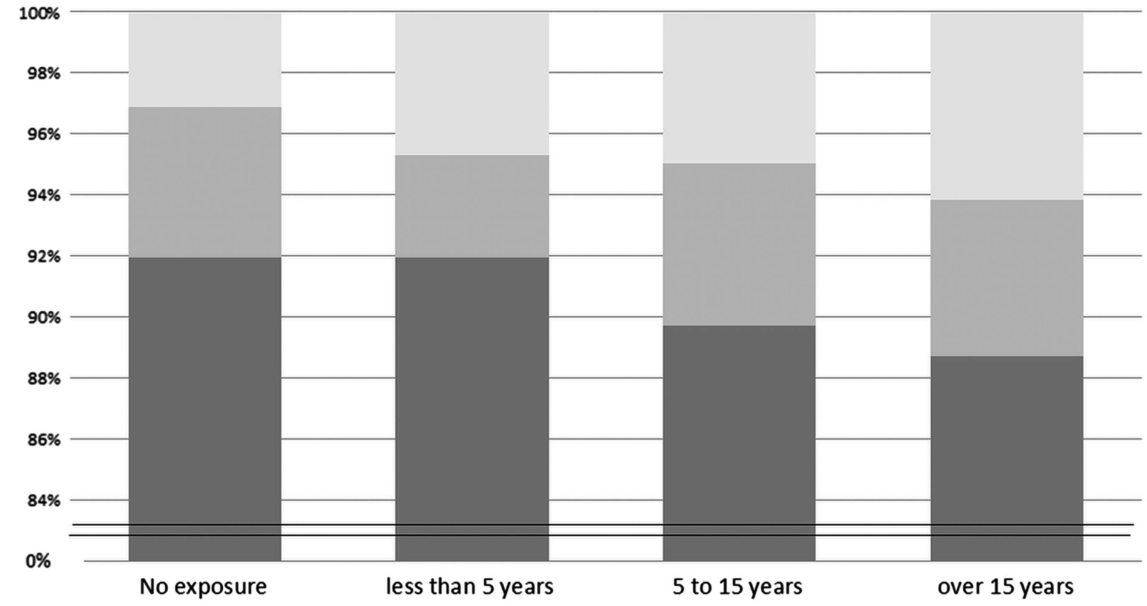

Dupuytren's disease with disability or surgery

Dupuytren's disease without disability or surgery

No Dupuytren's disease

Table 3 Univariate and multivariate analyses of Dupuytren's disease (yes vs no) and available factors assessed in the previous period in women

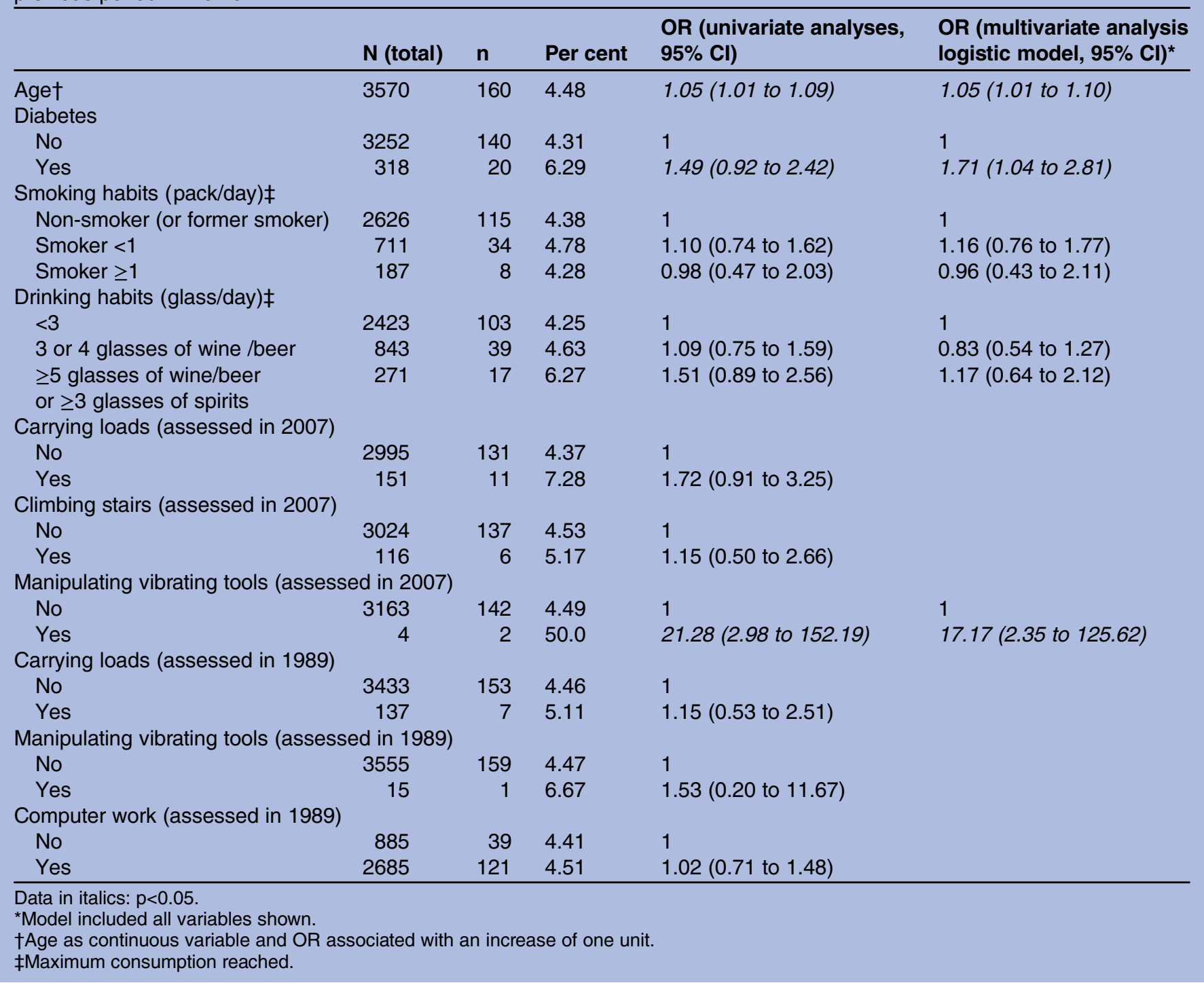


Table 4 Univariate and multivariate analyses of Dupuytren's disease (without limitations or surgery, with limitations or surgery, compared with reference class: no Dupuytren's disease) and available factors assessed in the previous period in women

\begin{tabular}{|c|c|c|c|c|c|c|c|c|c|}
\hline & \multirow[b]{2}{*}{$\begin{array}{l}\mathrm{N} \\
\text { (total) }\end{array}$} & \multicolumn{4}{|c|}{ Dupuytren's disease without limitations or surgery } & \multicolumn{4}{|c|}{ Dupuytren's disease with limitations or surgery } \\
\hline & & $\mathbf{n}$ & Per cent & $\begin{array}{l}\text { OR (univariate } \\
\text { analyses, } 95 \% \mathrm{Cl} \text { ) }\end{array}$ & $\begin{array}{l}\text { OR (multivariate analysis } \\
\text { logistic model, } 95 \% \mathrm{Cl})^{\star}\end{array}$ & $\mathbf{n}$ & $\begin{array}{l}\text { Per } \\
\text { cent }\end{array}$ & $\begin{array}{l}\text { OR (univariate } \\
\text { analyses, } 95 \% \mathrm{CI} \text { ) }\end{array}$ & $\begin{array}{l}\text { OR (multivariate analysis } \\
\text { logistic model, } 95 \% \mathrm{Cl})^{*}\end{array}$ \\
\hline Age† & 3570 & 82 & 2.30 & $1.04(0.98$ to 1.09$)$ & $1.04(0.98$ to 1.10$)$ & 78 & 2.18 & $1.06(1.01 ; 1.12)$ & 1.07 (1.01 to 1.13$)$ \\
\hline \multicolumn{10}{|l|}{ Diabetes } \\
\hline No & 3252 & 75 & 2.31 & 1 & 1 & 65 & 2.00 & 1 & 1 \\
\hline Yes & 318 & 7 & 2.20 & $0.97(0.45 ; 2.13)$ & $1.18(0.53$ to 2.61$)$ & 13 & 4.09 & 2.09 (1.14 to 3.83$)$ & 2.27 (1.22 to 4.24$)$ \\
\hline \multicolumn{10}{|c|}{ Smoking habits (pack/day) $\ddagger$} \\
\hline $\begin{array}{l}\text { Non-smoker (or } \\
\text { former } \\
\text { smoker) }\end{array}$ & 2626 & 62 & 2.36 & 1 & 1 & 53 & 2.02 & 1 & 1 \\
\hline Smoker $<1$ & 711 & 16 & 2.25 & 0.96 (0.55 to 1.67$)$ & 0.99 (0.54 to 1.82$)$ & 18 & 2.53 & $1.26(0.73$ to 2.16$)$ & $1.36(0.76$ to 2.41$)$ \\
\hline Smoker $\geq 1$ & 187 & 3 & 1.60 & 0.68 (0.21 to 2.19$)$ & 0.78 (0.24 to 2.55$)$ & 5 & 2.67 & $1.32(0.52$ to 3.35$)$ & $1.15(0.41$ to 3.27$)$ \\
\hline \multicolumn{10}{|c|}{ Drinking habits (glass/day)‡ } \\
\hline$<3$ & 2423 & 51 & 2.10 & 1 & 1 & 52 & 2.15 & 1 & 1 \\
\hline $\begin{array}{l}3 \text { or } 4 \text { glasses } \\
\text { of wine/beer }\end{array}$ & 843 & 23 & 2.73 & $1.30(0.79$ to 2.14$)$ & $1.06(0.60$ to 1.87$)$ & 16 & 1.90 & $0.89(0.50$ to 1.56$)$ & $0.63(0.33$ to 1.20$)$ \\
\hline $\begin{array}{l}\geq 5 \text { glasses of } \\
\text { wine/beer } \\
\text { or } \geq 3 \text { glasses } \\
\text { of spirits }\end{array}$ & 271 & 8 & 2.95 & $1.43(0.67$ to 3.05$)$ & $1.30(0.57$ to 3.00$)$ & 9 & 3.32 & $1.58(0.77$ to 3.25$)$ & 1.04 (0.46 to 2.39$)$ \\
\hline \multicolumn{10}{|c|}{ Climbing stairs (assessed in 2007) } \\
\hline No & 3024 & 69 & 2.28 & 1 & & 68 & 2.25 & 1 & \\
\hline Yes & 116 & 2 & 1.72 & $0.76(0.18$ to 3.14$)$ & & 4 & 3.45 & $1.54(0.55$ to 4.31$)$ & \\
\hline \multicolumn{10}{|c|}{ Manipulating vibrating tools (assessed in 2007) } \\
\hline No & 3163 & 70 & 2.21 & 1 & 1 & 72 & 2.28 & 1 & 1 \\
\hline Yes & 4 & 1 & 25.00 & 21.57 (1.93 to 240.79$)$ & 18.69 (1.61 to 216.66$)$ & 1 & 25.00 & 21.00 (1.88 to 234.10$)$ & $15.87(1.36$ to 184.70$)$ \\
\hline \multicolumn{10}{|c|}{ Carrying loads (assessed in 1989) } \\
\hline No & 3433 & 78 & 2.27 & 1 & & 75 & 2.18 & 1 & \\
\hline Yes & 137 & 4 & 2.92 & 1.29 (0.47 to 3.59$)$ & & 3 & 2.19 & $1.01(0.31$ to 3.24$)$ & \\
\hline \multicolumn{10}{|c|}{ Manipulating vibrating tools (assessed in 1989) } \\
\hline No & 3555 & 81 & 2.28 & 1 & & 78 & 2.19 & 1 & \\
\hline Yes & 15 & 1 & 6.67 & 2.99 (0.39 to 23.05$)$ & & 0 & 0.00 & 0.00 (0.00; Not calculable) & \\
\hline \multicolumn{10}{|c|}{ Computer work (assessed in 1989) } \\
\hline No & 885 & 20 & 2.26 & 1 & & 19 & 2.15 & 1 & \\
\hline Yes & 2685 & 62 & 2.31 & $1.02(0.61$ to 1.70$)$ & & 59 & 2.20 & $1.02(0.61$ to 1.73$)$ & \\
\hline
\end{tabular}


genetic factors, such as family history of Dupuytren's disease, hand trauma, epilepsy and anticonvulsant drug intake, that are considered to be associated with Dupuytren's disease, was not available. However, an association between these factors and vibration exposure and alcohol intake seems unlikely.

One of the strengths of our study is the relatively large size of the cohort. Since we had only one measure of Dupuytren's disease in 2012, that is, the number of reported cases of Dupuytren's disease, we studied factors associated with prevalent cases. However, assessment of work exposure 5 years before evaluation of the outcome, and the regular evaluation of alcohol intake and smoking throughout the follow-up period enabled us to be confident about the associations observed. Those were confirmed by information collected at inception, that is, 23 years before.

One important finding was confirmation in a large study of the association between alcohol consumption and Dupuytren's disease among men, with a dose-response relationship. ${ }^{11} 1316$ Although we might discuss the arbitrary cut-off, ${ }^{17}$ the association with reported limitations (or surgery) was a new finding because it has been described by clinicians before, but rarely reported in large cohort studies. ${ }^{1}{ }^{18}{ }^{19}$ Diabetes seemed to be related to the occurrence of Dupuytren's disease but not with limitations in men. Interestingly, it was associated with limitations in women. Ever smoking and heavy smoking were not found to be associated with Dupuytren's disease, which was unexpected considering the possible ischaemic aetiology of Dupuytren's disease, and the contrary findings in some recent studies. ${ }^{11} 16$ Absence of a relationship could be due to the small number of very heavy smokers (61 men and 26 women smoked 2 packs/day or more).

In terms of occupational exposure, only vibration was found to be related to Dupuytren's disease. Previous studies have shown that high cumulative occupational exposure to vibration (intensity $\mathrm{x}$ duration) was associated with Dupuytren's disease. ${ }^{13}{ }^{20-23}$ Although exposure to vibration during the working life was self-reported, it corresponded to a very specific exposure, probably with a low memory effect (workers tend to remember correctly this type of precise exposure). Hand-vibration transmitting tools in our cohort were mostly screw tools, common drills and (infrequently) pneumatic drills, where strenuous hand grip increases vibration damage. The role of high levels of vibration exposure is plausible, especially as a result of the local hypoxia and chronic ischaemia hypothesised in Dupuytren's contracture. ${ }^{4}$ Similar figures for the strength of the association found in published studies support the plausibility of a possible causal relationship. ${ }^{7}$ Carrying loads was studied because, with some tasks, such exposure is associated with manual work, and heavy forceful exposure during the working life was not available in the GAZEL cohort. However, no relationship was found here.
In addition to the well-established genetic factors, and despite the limitations discussed, this study emphasised the role of occupational hand-transmitted vibration exposure and alcohol consumption in Dupuytren's disease. The question of compensation in some cases with documented high levels of exposure should be reviewed, as should improvements of working conditions with a view to prevention.

\section{Author affiliations}

${ }^{1}$ Université de Versailles St-Quentin, Versailles, France

${ }^{2}$ Centre for Research in Epidemiology and Population Health (CESP), U1018,

"Population-Based Epidemiological Cohorts" Research Platform, INSERM, Villejuif, France

${ }^{3}$ AP-HP, Occupational Health Unit/EMS (Samu92), University Hospital of Paris West Suburb, Garches, France

${ }^{4}$ Plastic and Hand Department, Nice University, St Roch Hospital, Nice, France ${ }^{5}$ Laboratory of Ergonomics and Epidemiology in Occupational Health, LUNAM University, University of Angers, Angers, France

Acknowledgements The authors would like to thank EDF-GDF, especially the Service Général de Médecine de Contrôle and the 'Caisse centrale d'action sociale du personnel des industries électrique et gazière'. They would also like to thank the 'Population-Based Epidemiological Cohorts' research platform responsible for the GAZEL Cohort Study.

Contributors All authors contributed significantly to the manuscript and approved the final version. MZ, MC and MG were involved in the data collection, improved the analyses and commented the manuscript. $A D$ initiated the work, performed the main analyses and drafted the manuscript. $\mathrm{ZM}, \mathrm{CD}$ and $\mathrm{AL}$ discussed the project, improved the analyses and commented the manuscript.

Fundings The GAZEL Cohort Study was funded by EDF-GDF and INSERM and received grants from the 'Cohortes Santé TGIR Programme.'

Competing interest None.

Ethics approval Comité Consultatif National d'Ethique pour les Sciences de la Vie et de la Santé.

Provenance and peer review Not commissioned; externally peer reviewed. Data sharing statement No additional data are available.

Open Access This is an Open Access article distributed in accordance with the Creative Commons Attribution Non Commercial (CC BY-NC 3.0) license, which permits others to distribute, remix, adapt, build upon this work noncommercially, and license their derivative works on different terms, provided the original work is properly cited and the use is non-commercial. See: http:// creativecommons.org/licenses/by-nc/3.0/

\section{REFERENCES}

1. Townley WA, Baker R, Sheppard N, et al. Dupuytren's contracture unfolded. BMJ 2006;332:397-400.

2. Gudmundsson KG, Jonsson T, Arngrimsson R. Guillaume Dupuytren and finger contractures. Lancet 2003;362:165-8.

3. Dolmans $\mathrm{GH}$, Werker PM, Hennies HC, et al. Wnt signaling and Dupuytren's disease. N Engl J Med 2011;365:307-17.

4. Eaton C, Seegenschmiedt MH, Bayat A, et al., ed. Dupuytren's disease and related hyperproliferative disorders-principles, research, and clinical perspectives. Berlin, New York: Springer, 2011.

5. Dembe A. Occupation and disease: how social factors affect the conception of work-related disorders. Yale, CT: Yale University Press, 1996.

6. Liss GM, Stock SR. Can Dupuytren's contracture be work-related? review of the evidence. Am J Ind Med 1996;29:521-32.

7. Descatha A, Jauffret $P$, Chastang J-F, et al. Should we consider Dupuytren's contracture as work-related? A review and meta-analysis of an old debate. BMC Musculoskelet Disord 2011;12:96. 
8. Burge PD. Dupuytren's disease. J bone Joint Surg $\mathrm{Br}$ 2004;86:1088-9.

9. Hindocha S, mcgrouther DA, Bayat A. Epidemiological evaluation of Dupuytren's disease incidence and prevalence rates in relation to etiology. Hand 2009;4:256-69.

10. Hart MG, Hooper G. Clinical associations of Dupuytren's disease. Postgrad Med J 2005;81:425-8.

11. Godtfredsen NS, Lucht $\mathrm{H}$, Prescott E, et al. A prospective study linked both alcohol and tobacco to Dupuytren's disease. J Clin Epidemiol 2004;57:858-63.

12. Goldberg $\mathrm{M}$, Leclerc $\mathrm{A}$, Bonenfant $\mathrm{S}$, et al. Cohort profile: the GAZEL Cohort Study. Int J Epidemiol 2007;36:32-9.

13. Lucas G, Brichet A, Roquelaure $\mathrm{Y}$, et al. Dupuytren's disease: personal factors and occupational exposure. Am J Ind Med 2008:51:9-15.

14. Rayan GM. Clinical presentation and types of Dupuytren's disease. Hand Clin 1999;15:87-96, vii.

15. Lanting R, Broekstra DC, Werker PMN, et al. A systematic review and meta-analysis on the prevalence of Dupuytren disease in the general population of western countries. Plast Reconstr Surg 20 Nov 2013. Epub ahead of print.
16. Burke FD, Proud G, Lawson IJ, et al. An assessment of the effects of exposure to vibration, smoking, alcohol and diabetes on the prevalence of Dupuytren's disease in 97,537 miners. J Hand Surg Eur Vol 2007;32:400-6.

17. International Drinking Guidelines (Internet). (cité 2013 déc 6). http:// www.icap.org/table/Internationaldrinkingguidelines

18. Weinstein AL, Haddock NT, Sharma S. Dupuytren's disease in the Hispanic population: a 10-year retrospective review. Plast Reconstr Surg 2011:128:1251-6.

19. Lanting R, van den Heuvel ER, Westerink B, et al. Prevalence of Dupuytren disease in the Netherlands. Plast Reconstr Surg 2013:132:394-403.

20. Chanut JC. Dupuytren's disease. Arch Mal Prof 1963;24:621-5.

21. Cocco PL, Frau P, Rapallo M, et al. Occupational exposure to vibration and Dupuytren's disease: a case-controlled study. Med Lav 1987;78:386-92.

22. Thomas PR, Clarke D. Vibration white finger and Dupuytren's contracture: are they related? Occup Med (Lond) 1992;42:155-8.

23. Bovenzi M. Hand-arm vibration syndrome and dose-response relation for vibration induced white finger among quarry drillers and stonecarvers. Italian Study Group on Physical Hazards in the Stone Industry. Occup Environ Med 1994;51:603-11. 